\section{New plant for the manufacture of viscous polybutadienes}

Synthomer today announced the $\checkmark$ opening of a multi-million Euro investment at its new facility for the production of viscous polybutadienes at Stallingborough in the UK. These compounds are available under the brand name of Lithene and are sold globally for use in a diverse range of applications, including automotive sealants, mould release products, coating additives and rubber modifiers. Various investments mark the start of production for the new Litheneultra range of products, which can be used in other applications for viscous polybutadienes thanks to their improved quality and performance. Litheneultra will be available from September 2013, with maleinised grades being launched during the final quarter of this year.

"The development of Litheneultra comes in response to growing customer demand for low-odour and low-VOC applications. This latest investment reflects a continued commitment to providing customers with market leading products for a wide range of applications and is one phase of a wider development programme for our Lithene product range," said Ian Wilkinson, General Manager Performance Polymers.

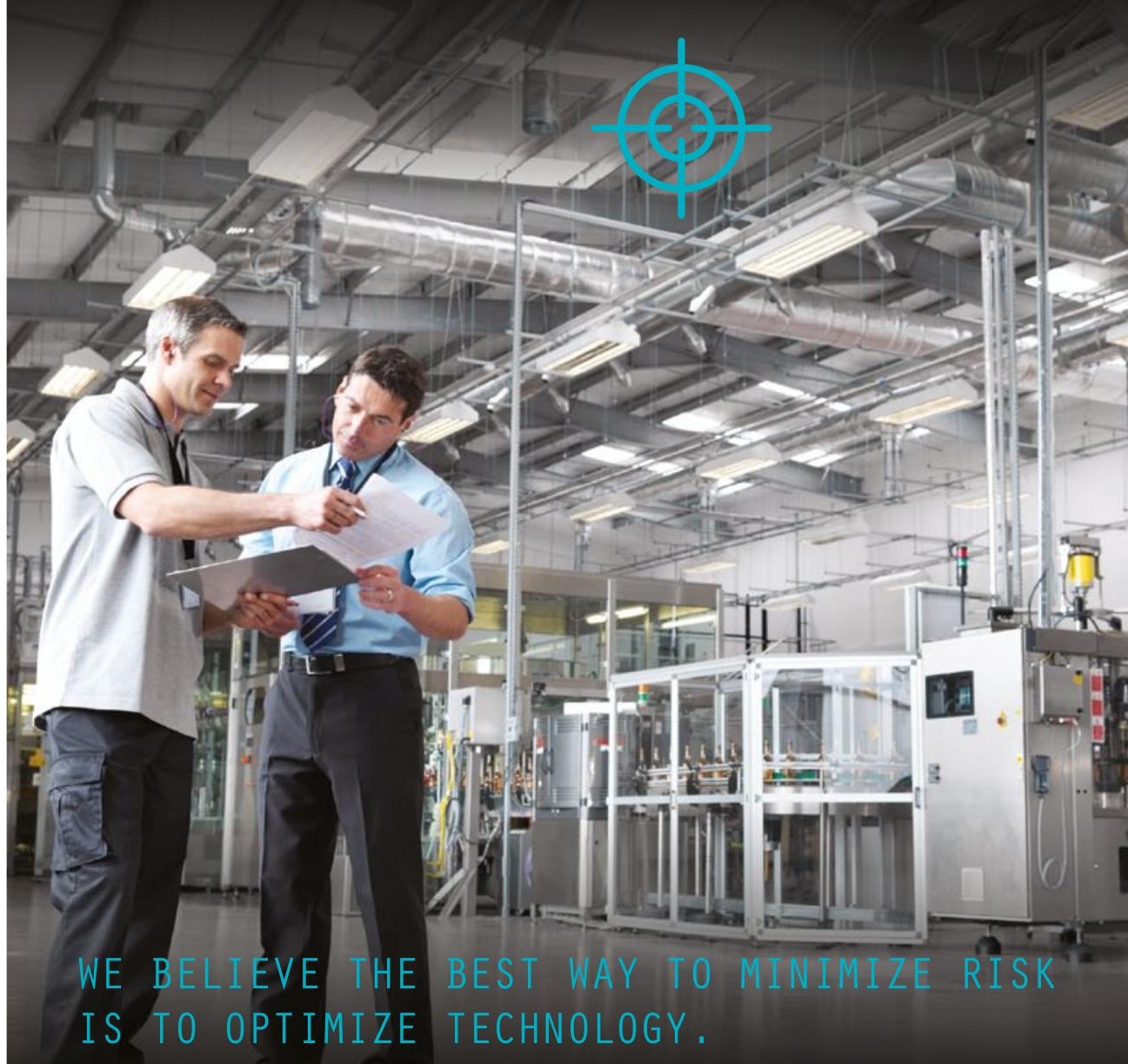

When you deal with multiple suppliers, you multiply your own risk of failure. The potential for issues like cost and product incompatibility increases exponentially. And when there is a problem, which supplier is going to take responsibility? The Dymax Edge gives you an entire toolbox of advanced light-cure resources. More important, as a single-source solution provider, we have an understanding of your application process others can't match. Which means we give you a solution that's more effective every step of the way. And with the Dymax Edge, there's no finger pointing. Just problem solving. The choice is yours. Take on the hassle of multiple suppliers. Or take control of risk with the Dymax Edge. To learn more, visit edge.dymax.com.

\section{UA L I S T EN. ENV I S I ON. DEL IVER.}

+49 (0) 6119627900

WWW, DYMAX, DE

\title{
Expanded product portfolio for the Polish market
}

$n$ the framework of a new partnership,
the Polish branch of Bodo Möller Chemie and DOG Chemie (Deutsche Oelfabrik Gesellschaft) have agreed that Bodo Möller Chemie will sell silane, silane blends and additives for coatings from DOG Chemie on the Polish market and in Lithuania and Latvia as of immediately. These products are applied in numerous different coating systems and the pre- treatment of fillers and are used in adhesives, jointing compounds and textile equipment.

The Bodo Möller Chemie group has eleven branches worldwide - besides Poland and Germany, these are to be found in Scandinavia, Poland, South Africa and the Benelux countries. With its special product ranges geared towards the needs of the market involved in each case, Bodo Möller Chemie acts as a link between manufacturers of specialty chemicals and the processing industry. In addition to the products of DOG Chemie, the product portfolio of Bodo Möller Chemie includes adhesives based on epoxy resins, polyurethane or methyl methacrylate as well as a wide range of additives for coating systems. 